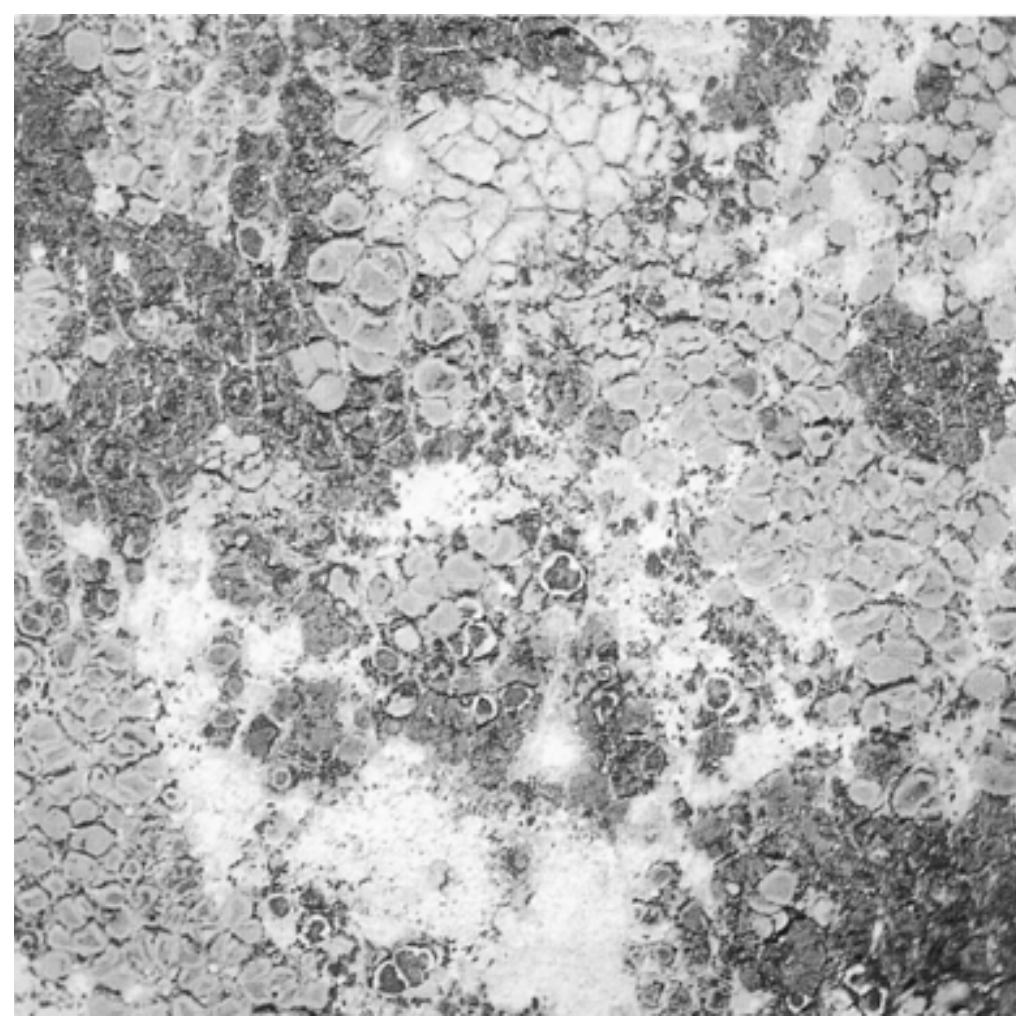

\title{
Inventario de la vegetación y estudio de la interferencia biocida con los materiales pétreos del yacimiento del cerro de la plaza de armas de Puente Tablas (JAÉn)
}

\author{
Marta Sameño Puerto \\ Rosario Villegas Sánchez \\ Departamento de Análisis \\ Instituto Andaluz de \\ Patrimonio Histórico \\ Jorge Garcia Rowe \\ Departamento de \\ Biología Vegetal y Ecología
}

Fac. de Farmacia, Universidad de Sevilla as rocas pueden sufrir procesos de alteración de tres tipos: físicos, químicos y biológicos. La alteración biológica se debe a la influencia ejercida por los vegetales, superiores e inferiores, y por los animales. La vegetación puede producir alteraciones por varias causas:

Musgos y líquenes: actúan como acumuladores de humedad. El sustrato permanece húmedo más tiempo y esto favorece su alteración. No obstante, los líquenes pueden ejercer un efecto protector contra agentes degradantes puesto que forman un revestimiento sobre la superficie de la piedra. 




Plantas superiores: sus raíces pueden provocar efectos mecánicos de disgregación de materiales, provocando desprendimientos periódicos. Sin embargo, la vegetación es beneficiosa en cuanto a que retarda la erosión, estabiliza la pendiente, etc.

Los lienzos de muralla y demás estrucuras de habitación (fig. I) sacadas a la luz por las excavaciones en el yacimiento arqueológico de Puente Tablas, sufren un fuerte problema de colonización de diversas especies, fundamentalmente de plantas superiores. Se ha llevado a cabo un análisis de la vegetación existente, determinando y describiendo cada especie, así como su correspondiente biotipo que indica de qué forma dicha especie altera el sustrato.

Generalmente, cuando se restaura un edificio o monumento de piedra, los principales objetivos incluyen tratamientos de limpieza, de ahí la importancia del estudio sobre tratamientos biocidas efectivos que limpien, inhiban y erradiquen crecimientos macro y microbiológicos en obras de arte pétreas.

La efectividad de los biocidas ha sido ampliamente estudiada, pero no así el efecto de estas sustancias sobre los componentes de la piedra. El objetivo de este estudio es verificar el efecto de los tratamientos biocidas sobre los materiales pétreos, utilizando diversos ensayos y métodos de aplicación de los productos (L. Schnabel, 1991).

Los productos biocidas, su concentración y el método de aplicación se han seleccionado para subrayar la posible interacción de los mismos con la superficie de la piedra. Las características de las piedras ensayadas se han determinado antes y después del tratamiento biocida. Se han usado las siguientes técnicas: medida de la absorción de agua por capilaridad y de la alteración cromática y observaciones con microscopio electrónico de barrido (M. P. Nugari, P. Pallechi y D. Pinna, 1993). Por último se han realizado ensayos de envejecimiento acelerado.

\section{INVENTARIO DE LA VEGETACIÓN}

\section{Biotipos}

Se distinguen distintos biotipos que afectan desigualmente a las estructuras emergentes (J. García Rowe y C. Sáiz-Jiménez, 1991).

\section{Biotipos de líquenes y briofitos}

Crustáceo. Talo fuertemente adherido al sustrato por toda su superficie, carece de córtex inferior y se fija a través de las hifas del hongo que penetran en el sustrato. El talo puede desarrollarse totalmente incrustado en rocas (endolítico) o bien sobre el sustrato (epilítico). Desde el punto de vista de la erosión química y mecánica son los talos que presentan un mayor efecto negativo. Foliáceo. El talo presenta un córtex inferior bien definido y se adhiere al sustrato mediante ricinas producidas por el hongo del líquen. La erosión química es menos acusada, si bien la erosión mecánica producida por las ricinas puede ser mayor que en el caso anterior.

Escuamuloso. Talo formado por escamas con los bordes laxamente adheridos al sustrato, a veces superpuestas. Algunos no tienen córtex inferior, otros sí.

Fruticuloso. Talo que tiene la forma de un pequeño arbusto erecto o pendiente y que se fija al sustrato por un punto (disco de fijación), por lo cual la erosión química es mucho menos acusada, pero la erosión mecánica es igual o superior que en el caso de los foliáceos. Las ramificaciones pueden ser cilíndricas o aplanadas (lacinias).

Folioso. Biotipo de briofitos que supone el mismo impacto que los talos foliáceos de los líquenes porque se adhieren al sustrato mediante rizoides.

Taloso. Biotipo de hepáticas. Similar en cuanto a impacto al caso anterior.

\section{Biotipos de plantas superiores}

Terófito. Plantas que cumplen su ciclo vital completo en la estación favorable (anuales). No hay estructuras perdurables excepto las semillas. El grado de desarrollo alcanzado por los terófitos depende de la especie considerada.

Hemicriptófito. Plantas en las que la parte aérea muere cada año, quedando las yemas perdurantes a ras del suelo. No suelen alcanzar tallas tan altas como los terófitos, pero al ser perennes la erosión mecánica puede ser más grave para el sustrato.

Caméfito. Plantas leñosas de poco porte, con yemas perdurantes que no se elevan más de 20-25 $\mathrm{cm}$ del suelo. 
Criptófito. Plantas cuyas partes perdurantes quedan bien protegidas bajo la superficie del sustrato, acomodándose en fisuras, grietas y superficies de escorrentía. Desde el punto de vista de la erosión mecánica son las que pueden provocar un mayor daño.

Fanerófito. Plantas leñosas arbóreas. Su grado de desarrollo se ve claramente condicionado por la accesibilidad y la riqueza del sustrato así como por la abundancia de agua. Desde el punto de vista mecánico son las más perjudiciales debido al tamaño y volumen que pueden alcanzar sus raíces.

\section{Material y métodos}

La información necesaria para la realización de este estudio se ha obtenido de las siguientes fuentes: el material bibliográfico utilizado y el material recolectado en las excursiones realizadas al yacimiento arqueológico.

El proceso seguido se estructura en 3 fases: recogida del material, determinación del mismo y elaboración de datos.

Las muestras tomadas para el estudio del biodeterioro, son las que aparecen sobre las estructuras excavadas o próximas a ellas.

\section{Líquenes}

La toma de muestra se ha realizado en aquellos puntos de la superficie de la piedra en los que las alteraciones eran más significativas y representativas. Se han registrado las características del área elegida, sustrato, orientación, etc.

Se han tomado muestras con distintas especies en zonas de distinta ecología (ver fig. 2). También se ha tomado I muestra de la piedra que presentaba pequeñas punteaduras quizás producidas por los talos de líquenes endolíticos (biopitting).

Para su determinación y descripción se ha consultado la clave de P. Ozenda y G. Clauzade (1970) y se han utilizado los siguientes reactivos, indicando en cada caso si la reacción es positiva y el color:

K: Solución concentrada de $\mathrm{KOH}$ en agua.

Cl: Hipoclorito sódico en solución acuosa comercial (lejía concentrada).

I: $\quad$ Solución de yodo en yoduro potásico.

$\mathrm{N}$ : Acido nítrico concentrado.

\section{Briofitos}

Se han tomado 4 muestras de musgos aún estériles. Sin embargo no se ha observado que estos organismos intervengan de forma significativa en los procesos de alteración biológica del yacimiento, por lo que no se procedió a su determinación.

\section{Plantas superiores}

En el caso de Puente Tablas se trata de una vegetación típica de lugares secos e incluso semiáridos (fig. 3), que se encuentra en los afloramientos calizos y en algunas laderas y llanuras no aptas para el cultivo. También en los márgenes de caminos.

La toma de muestras se ha llevado a cabo en las visitas realizadas al yacimiento. Para su determinación y descripción se ha utilizado la clave de G. Bonnier y G. de Layens (1988) y la de B. Valdés, S. Talavera y E. Fernández-Galiano (eds.) (1987).

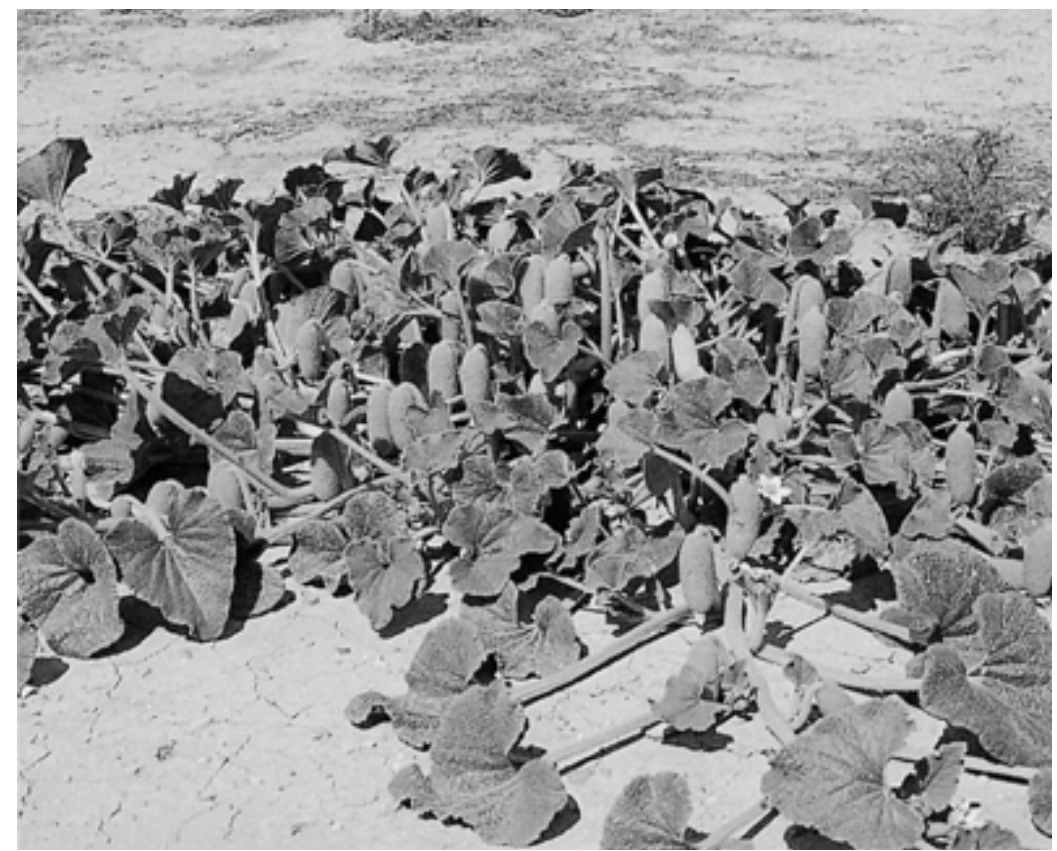

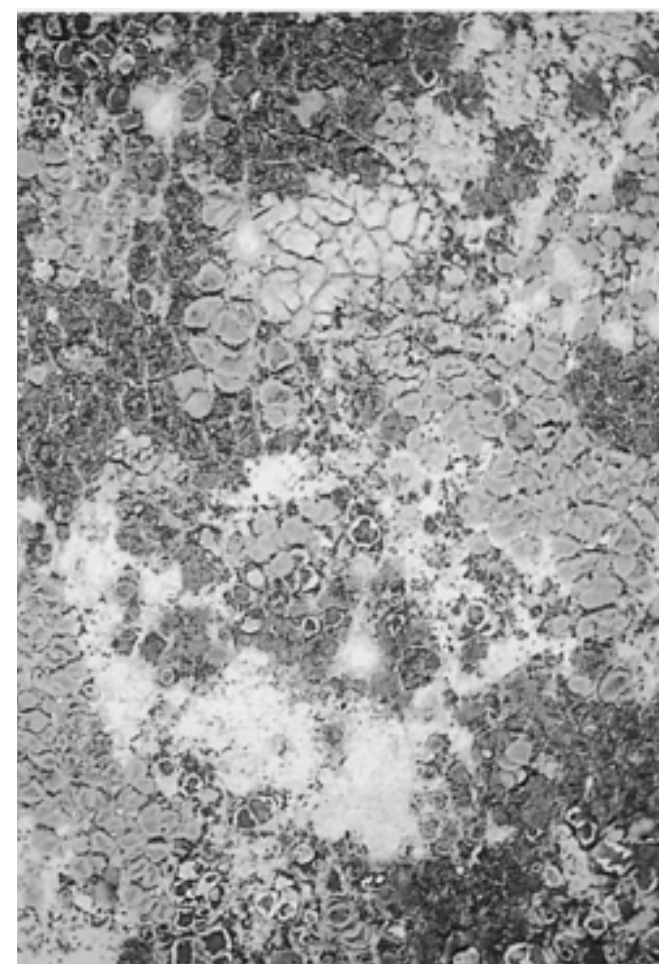


Líquenes

Se ha realizado un listado de las distintas especies.

\begin{tabular}{|c|c|c|c|}
\hline ESPECIE & BIOTIPO & ESPECIE & BIOTIPO \\
\hline Acarospora cervina (Pers.) Massal & Escuamuloso & Candelariella xanthostigma (Pers.) Lett. & Crustáceo \\
\hline Acarospora laqueata Stizenb. & Escuamuloso & Collema tenax (Sw.) Ach & Foliáceo \\
\hline Aspicilia hoffmanii (Ach.) Flag. & Crustáceo & Lecania erysibe (Ach.) Mudd. & Crustáceo \\
\hline Aspicilia radiosa H. Magn. & Crustáceo & Lecanora muralis (Schreb.) Rabenh & \\
\hline Caloplaca erytrocarpa (Pers.) Zw. & Crustáceo & var. versicolor (Pers.) Tuck. & Crustáceo \\
\hline Caloplaca sp1 & Crustáceo & Lecanora prominens Clauz. et Vèzda. & Crustáceo \\
\hline Caloplaca sp2 & Crustáceo & Poeltinula aff. cerebrina (DC.) Hafellner & Crustáceo \\
\hline Caloplaca teicholyta (Ach.) Steiner & Crustáceo & Rinodina calcarea (Hepp.) Arn. & Crustáceo \\
\hline C. velana (Massal) Du Rietz. var. dolomitícola (Hue) Zahlbr. & Crustáceo & Verrucaria sp. & Crustáceo \\
\hline
\end{tabular}

Plantas superiores

Se ha realizado un listado de las distintas especies.

\begin{tabular}{|c|c|c|c|c|c|}
\hline ESPECIE & LOCALIZACIÓN & BIOTIPO & ESPECIE & OCALIZACIÓN & BIOTIPO \\
\hline Aegilops ovata L. & M. & Terófito & Chamaemelum nobile (L.) All. & C. & Hemicriptófito \\
\hline Allium pallens $\mathrm{L}$. & M. & Criptófito & Cichorium intybus L. & M. & Hemicriptófito \\
\hline Althaea Iongiflora Boiss \& Reuter & & Terófito & Cleonia lusitanica L. & M. & Terófito \\
\hline Alyssum symplex (L.) Rudolphi & M./C & Terófito & Convolvulus althaeoides L. & C & Hemicriptófito \\
\hline Anacyclus clavatus (Desf.) Pers. & C. & Terófito & Convolvulus arvensis L. & C. & Hemicriptófito \\
\hline Anchusa azurea & C. & Hemicriptófito & Crepis vesicaria $\mathrm{L}$. & C. & Terófito \\
\hline Anchusa undulata subsp. granatensis & & & Dactylis glomerata $\mathrm{L}$. & M./C. & Hemicriptófito \\
\hline (Boiss.) Valdés & C. & Hemicriptófito & Daucus carota L. subsp. carota & M. & Hemicriptófito \\
\hline Anthemis arvensis $\mathrm{L}$. & M./C. & Terófito & Diplotaxis virgata (Cav.) DC. & M./C. & Terófito \\
\hline Artemisia barrelieri Besser & C & Caméfito & Ecbalium elaterium L. & C. & Hemicriptófito \\
\hline Asparagus albus $\mathrm{L}$ & M. & Caméfito & Echinops strigosus L. & M. & Hemicriptófito \\
\hline Asphodelus fistulosus L & C. & Hemicriptófito & Echium creticum L. & C. & Hemicriptófito \\
\hline Asteriscus spinosus L. & C. & Terófito & Erodium ciconium (L.) L'Hér. & M./C. & Hemicriptófito \\
\hline Astragalus hamosus L. & C. & Terófito & Erodium malacoides (L.) L'Hér. & C. & $\overline{\text { Terófito }}$ \\
\hline Atractylis cancellata L. & M. & Terófito & Eruca sativa Miller subsp. Iongirostris & & \\
\hline Avena barbata Pott \& Link & & & (Uechtr.) Jahandiez \& Maire & M. & Terófito \\
\hline subsp. barbata & C. & Terófito & Eryngium campestris $L$. & C. & Hemicriptófito \\
\hline Avena sativa L. & M. & Terófito & Euphorbia serrata L. & M. & Hemicriptófito \\
\hline Ballota hirsuta Bentham & C. & Hemicriptófito & Evax pigmaea L. & M. & Terófito \\
\hline Bellardia trixago (L.) All. & M. & Terófito & Filago lutescens Jordan & C. & Terófito \\
\hline Bombycilaena discolor (Pers.) Laínz & M. & Terófito & Foeniculum vulgare Miller subsp. & & \\
\hline Brachypodium distachyon (L.) Beauv. & M. & Terófito & piperitum (Ucria) Sweet & C. & Hemicriptófito \\
\hline Bromus matritensis $\mathrm{L}$. & C. & Terófito & Fumaria faurei (Pugsley) Lidén & C. & Terófito \\
\hline Bromus rubens $\mathrm{L}$. & M./C. & Terófito & Galium aparine L. & C. & Terófito \\
\hline Bupleurum semicompositum L. & M. & Terófito & Galium parissiense L. & C. & Terófito \\
\hline Cachrys sicula L. & M. & Hemicriptófito & Galium verrucosum Hudson & C. & Terófito \\
\hline Caléndula arvensis $\mathrm{L}$. & C. & Terófito & Glacium corniculatum (L.) J.H.Rudolph C. & & Hemicriptófito \\
\hline Capparis ovata Desf. & C. & Caméfito & Hedysarum glomeratum F. G. Dietrich $\mathrm{M}$. & & Terófito \\
\hline Carduus bourgeanus Boiss. \& Reuter & C. & Hemicriptófito & Hordeum murinum subsp. & & \\
\hline Catanche lutea $\mathrm{L}$. & M./C. & Terófito & leporinum (Link) Arcangeli & C. & Terófito \\
\hline Centaurea mellitensis $\mathrm{L}$. & M./C. & Terófito & Lamarckia aurea (L.) Moench. & C. & Terófito \\
\hline
\end{tabular}




\begin{tabular}{|c|c|c|}
\hline $\begin{array}{l}\text { Leontodon longirostis } \\
\qquad \text { (Finch \& P.D. Sell) Talavera }\end{array}$ & M. & Terófito \\
\hline Lepidium subulatum L. & C. & Caméfito \\
\hline Linaria latifolia Desf. & C. & Terófito \\
\hline Linum strictum $\mathrm{L}$. & C. & Terófito \\
\hline Linum tenue Desf. & M. & Terófito \\
\hline Lygeum spartum L. & M. & Hemicriptófito \\
\hline Marrubium vulgare L. & C. & Hemicriptófito \\
\hline Medicago minima (L.) Bartal & M./C. & Terófito \\
\hline Medicago polymorpha L. & & Terófito \\
\hline Moricandia arvensis L. & M. & Hemicriptófito \\
\hline Muscari commosum (L.) Miller & M./C. & Criptófito \\
\hline Nigella papillosa G. López & M. & Terófito \\
\hline Ononis natrix L. & M./C. & Hemicriptófito \\
\hline Ononis viscosa $\mathrm{L}$. & M. & Terófito \\
\hline Onopordum nervosum Boiss. & C. & Hemicriptófito \\
\hline Onosma tricerosperma Lag. & M. & Hemicriptófito \\
\hline Ornithogalum narbonense L. & M. & Criptófito \\
\hline Papaver hybridum L. & C. & Terófito \\
\hline Papaver rhoeas $\mathrm{L}$. & C. & Terófito \\
\hline Parentucellia viscosa (L.) Caruel M. & & Terófito \\
\hline Piptaterum miliaceum (L.) Cosson & C. & Hemicriptófito \\
\hline Plantago afra L. & C. & Terófito \\
\hline Plantago albicans $L$. & M./C. & Hemicriptófito \\
\hline Plantago bellardii All. & C. & Terófito \\
\hline Plantago lagopus L. & M./C. & Hemicriptófito \\
\hline Plantago lanceolata L. & C. & Hemicr \\
\hline
\end{tabular}

\begin{tabular}{|c|c|c|}
\hline Platycapnos spicata (L.) Bernh. & C. & Terófito \\
\hline \multicolumn{3}{|l|}{ Rapistrum rugosum (L.) } \\
\hline All. subsp. lineanum & M. & Terófito \\
\hline Reseda lanceolata Lag. & C. & Terófito \\
\hline Reseda phyteuma L & C. & Terófito \\
\hline Retama sphaerocarpa (L.) Boiss. C. & & Caméfito \\
\hline Rubia peregrina $L$. & C. & Hemicriptófito \\
\hline Salvia argentea L. & $\mathrm{M}$. & Hemicriptófito \\
\hline Salvia verbenaca $\mathrm{L}$. & M. & Hemicriptófito \\
\hline Scabiosa stelata L. & $\mathrm{M}$. & Terófito \\
\hline Scorzonera laciniata L. & C. & Hemicriptófito \\
\hline Silene colorata Poiret & C. & Terófito \\
\hline Silene inflata (Salisb.) Sm. & $\mathrm{M}$. & Hemicriptófito \\
\hline Silene nocturna L. & C. & Terófito \\
\hline \multicolumn{3}{|l|}{ Silene rubella L. subsp. bergiana } \\
\hline (Lindman) Malagarriga & C. & Terófito \\
\hline Sonchus asper (L.) Hill & C. & Terófito \\
\hline Sonchus tenerrimus L. & C. & Hemicriptófito \\
\hline Stipa capensis Thumb. & C. & Terófito \\
\hline Stipa parviflora Desf. & M. & Hemicriptófito \\
\hline Thapsia villosa $\mathrm{L}$. & C. & Hemicriptófito \\
\hline \multicolumn{3}{|l|}{ Thymus zygis Loefl. \& L. subsp. } \\
\hline gracilis (Boiss.) R. Morales & M. & Caméfito \\
\hline Tragopogon porrifolius L. & & Hemicriptófito \\
\hline Trifolium stellatum L. & M. & Terófito \\
\hline Trigonella mospeliaca L. & & Terófito \\
\hline
\end{tabular}

\section{Discusión}

Actualmente los líquenes no juegan un papel importante en el deterioro de las estructuras presentes en el yacimiento, esto es debido a que éstas han sido descubiertas no hace mucho tiempo; no obstante se ha procedido a su determinación con objeto de conocer las distintas especies existentes, ya que los líquenes son los organismos que inician la sucesión biológica, seguidos por los briofitos y las plantas superiores.

De los biotipos presentes el más abundante es el crustáceo, se observa algún escuamuloso y algún foliáceo.

En cuanto a las plantas superiores, se trata de una vegetación típica de lugares secos e incluso semiáridos que se encuentra frecuentemente en los márgenes de los caminos. Se han observado matorrales de distintas especies adaptadas a la sericidad: presencia de pelos en el envés de la hoja, hojas con bordes revolutos, etc. El objetivo de estas adaptaciones es evitar la pérdida de agua por transpiración.

Las familias que más abundan son las compuestas, las gramíneas y las papilonáceas. También existen algunas labiadas. Por otro lado, se ha visto que el porcentaje de las distintas familias es muy similar en las 2 localidades de muestreo.
Con respecto a los biotipos presentes, el más abundante es el terófito seguido por el hemicriptófito. También se han inventariado, en menor porcentaje, muchos caméfitos (arbustos) y algunos criptófitos (plantas bulbosas). Así pues, esto nos da una idea del tipo de alteración producida.

\section{Conclusiones}

El análisis y determinación de la flora y la vegetación que crece en el yacimiento debe ser considerado como una contribución importante e imprescindible al estudio de tratamientos biocidas para la conservación. Estos análisis son útiles para el control de la vegetación ruderal y el biodeterioro. El estudio de los distintos biotipos que predominan en el yacimiento han ayudado a la posterior elección de los biocidas que se van a emplear para su control.

\section{INTERFERENCIA DE LOS BIOCIDAS CON LOS MATERIALES PÉTREOS}

\section{Materiales}

\section{Litotipos}

Se ha usado el tipo de piedra característico del yacimiento, una caliza micrítica (caliza roja), que presenta un cierto porcentaje de hierro en su compo- 


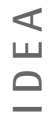

sición, y una caliza dolomítica (caliza gris). Se han utilizado probetas de $2 \times 2 \times 5 \mathrm{~cm}$.

\section{Productos herbicidas}

Los herbicidas utilizados han sido

(C. de Liñán Vicente, 1993):

1) PARACUAT, 20\%, p/v. LS. Referido como producto A.

2) GLIFOSATO, $18 \%$ + MCPA, sal isopropilamina, I8\%, p/v. LS. Referido como producto B.

3) TRIBENURON, $25 \%$ + TIFENSULFORON, 50\%. GR. Referido como producto $C$.

Se han disuelto en agua destilada a unas concentraciones que pueden reproducir el efecto de tratamientos repetidos (tratamientos estacionales). Los dos primeros se han usado al 2,5\% y el último al I \%.

\section{Aplicación de los herbicidas}

Los herbicidas se han aplicado de distinta forma según el ensayo al que se fueran a someter las probetas. Antes de aplicar los productos, se han lavado las muestras con agua destilada y se han secado a $60^{\circ} \mathrm{C}$ (ICR-CNR, 1985).

Impregnación por capilaridad. Las probetas se colocan sobre papel de filtro impregnado en los productos durante 24 horas. Las muestras así tratadas se usan para determinar la alteración cromática y la absorción de agua por capilaridad.

Impregnación por inmersión de las muestras durante 48 horas. Dichas muestras se han utilizado para la observación al SEM de las posibles alteraciones producidas.

Gráfica I. Caliza gris. Alteración acelerada

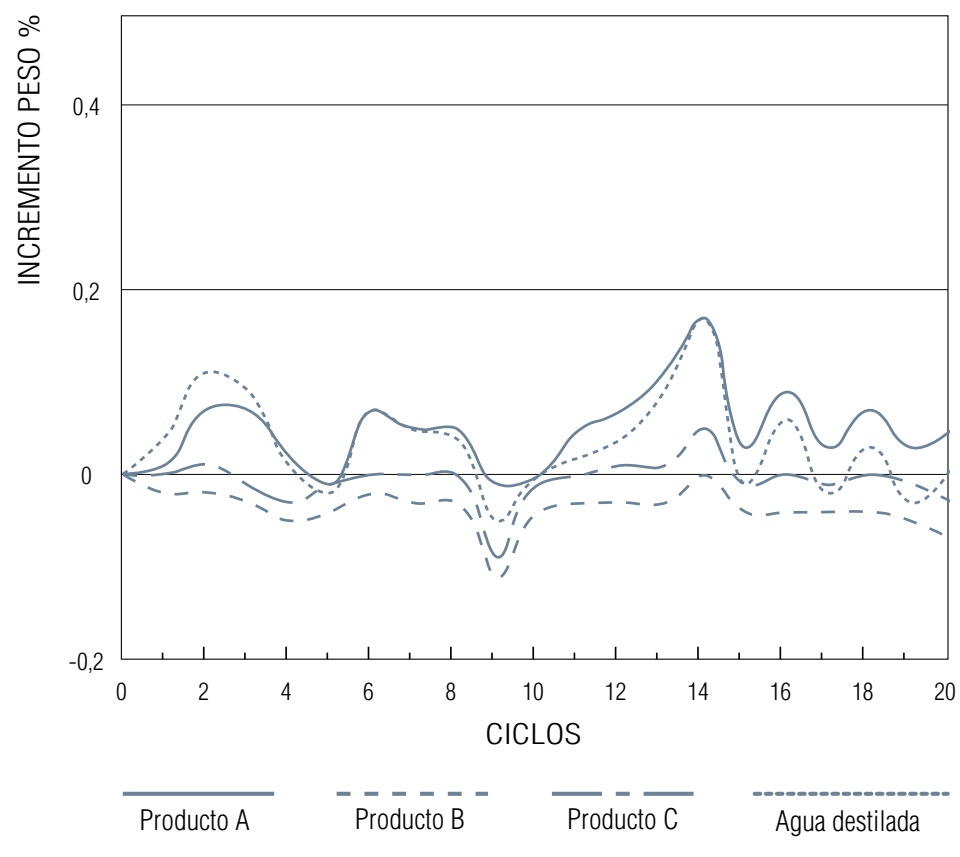

\section{Métodos de análisis y ensayos}

\section{Absorción de agua por capilaridad}

El ensayo de capilaridad se realiza sobre probetas previamente lavadas con agua destilada y secadas en estufa. Las probetas se colocan sobre una capa de papel de filtro que se mantiene saturado de agua durante todo el ensayo, cuidando de que el agua no toque las caras laterales de la probeta, de forma que penetre en ella sólo por la cara inferior (ICR-CNR, 1985). Las medidas se han realizado con 3 muestras de cada tipo de caliza, con cada uno de los 3 herbicidas, antes y después de la impregnación.

\section{Microscopio electrónico de barrido}

La microscopía electrónica de barrido es muy valiosa para el estudio de diversos mecanismos responsables de la alteración de la piedra:

- la formación y crecimiento de cristales en la superficie tras el tratamiento biocida,

- la corrosión, lavado o disolución de constituyentes minerales como consecuencia de las soluciones ácidas,

- el crecimiento sobre la piedra de organismos tales como bacterias, algas, hongos y líquenes, con las correspondientes consecuencias físicas y químicas.

La principal ventaja de este método se basa en la posibilidad de realizar microanálisis, en una zona o punto previamente seleccionados, mediante un detector de espectrometría de energía dispersada (ICR-CNR, 198I).

\section{Color}

El posible cambio de color que se produce en las probetas tras el tratamiento biocida es cuantificado mediante el "Munsell soil color charts". La medida del color se ha realizado en las muestras tratadas por capilaridad con los herbicidas.

\section{Ensayo de alteración acelerada}

El ensayos de envejecimiento acelerado ha consistido en:

- pesada inicial del material,

- inmersión en las 3 soluciones de los distintos biocidas y en la solución testigo (agua destilada) durante $3 \mathrm{~h}$,

- secado en estufa a $60^{\circ} \mathrm{C}$ durante $20 \mathrm{~h}$,

- estabilización a temperatura ambiente durante Ih,

- pesada del material.

Este ciclo se repite 20 veces (RILEM-VIa, VIb, V-2, V3; DIN 52104, 521।I, 52250; ASTM C-67, C-88, C218, C-290, C-29|; UNE 7-062, 7-। 36, 7-192, 22-174, 22-। 84, 22-193). Se han realizado observaciones al microscopio electrónico de barrido a la mitad $\left(10^{\circ} \mathrm{ci}-\right.$ clo) y al final $\left(20^{\circ}\right.$ ciclo $)$ del ensayo. 


\section{Resultados y discusión}

\section{Absorción de agua por capilaridad}

Los resultados aparecen en la tabla I. Se ha observado que la absorción de agua después del tratamiento biocida en ambos tipos de caliza disminuye apreciablemente en todos los casos, salvo en el producto A. Esta variación de absorción de agua puede ser debida a cambios producidos en la microporosidad de la superficie. muy evidente de la piedra tras la impregnación por inmersión. La caliza gris presenta en su superficie, tras el tratamiento con el producto $B$, unos cristales de aproximadamente $400 \mu \mathrm{m}$; mientras que los cristales que presenta la caliza roja son más pequeños y menos numerosos, lo cual puede ser debido a la presencia de óxido de hierro en la piedra (fig. 5 y 6). Un microanálisis de estos cristales muestra un pico de calcio y otro menor de fósforo, lo que indica una posible reacción del herbicida con la piedra.

Tabla I. Absorción de agua por capilaridad $\left(\mathrm{mg} / \mathrm{cm}^{2}\right)$

\begin{tabular}{|c|c|c|c|c|c|c|c|c|}
\hline \multicolumn{5}{|c|}{ CALIZA ROJA } & \multicolumn{4}{|c|}{ CALIZA GRIS } \\
\hline & $30 \mathrm{~min}$ & $60 \mathrm{~min}$ & $3 \mathrm{~h}$ & $24 \mathrm{~h}$ & $30 \mathrm{~min}$ & $60 \mathrm{~min}$ & $3 \mathrm{~h}$ & $24 \mathrm{~h}$ \\
\hline$A$ & 38 & 47 & 58 & 84 & 26 & 26 & 26 & 36 \\
\hline$A^{*}$ & 33,2 & 42 & 61,6 & 79,2 & 15,2 & 16,4 & 26,4 & 37,2 \\
\hline$B$ & 36 & 45 & 57 & 80 & 25 & 25 & 26 & 35 \\
\hline$B^{*}$ & 7,2 & 8 & 29,6 & 68 & 10,4 & 8 & 10,8 & 5,2 \\
\hline C & 37 & 47 & 57 & 80 & 24 & 25 & 26 & 36 \\
\hline$C^{*}$ & 25,2 & 32,4 & 38,4 & 48,4 & 10 & 9,6 & 14,4 & 19,6 \\
\hline
\end{tabular}

$A, B, C=$ Antes del tratamiento. $\quad A^{*}, B^{*}, C^{*}=$ Después del tratamiento con los distintos productos.

En ambos tipos de piedra el tratamiento con el producto $\mathrm{B}$ disminuye considerablemente la absorción, si bien en la caliza rojiza esta disminución es muy grande al inicio del ensayo y algo menor al final. Este resultado puede estar relacionado con la alta viscosidad del producto u otras características químicas. Con el producto C, la disminución inicial es menor, pero al final del ensayo la reducción es mayor que en el caso anterior (para la caliza roja). Las muestras tratadas con el producto $A$ no muestran variaciones significativas.

\section{Alteración cromática}

La alteración cromática se muestra en la tabla 2. Para cuantificar el posible cambio de color producido en las distintas muestras de piedra se ha utilizado el "Munsell soil color charts". El tratamiento herbicida causa variaciones cromáticas, con respecto al color obtenido con agua destilada, en la caliza gris, sin embargo no se ha observado variación en la caliza roja (fig. 4).

La alteración es evidente en la caliza gris tratada con el producto A y el B. Con el producto A la piedra muestra un evidente color verdoso (el mismo que el del herbicida). En contraste, el tratamiento con el producto $B$ causa una coloración blanquecina (gris más claro). Sin embargo, ambas alteraciones no aparecen cuando el contacto piedra-biocida es menos intenso, por ejemplo por pulverización.

\section{Observación al SEM}

Las observaciones realizadas con el microscopio electrónico de barrido, no han mostrado una alteración
Tabla 2. Variación cromática

\begin{tabular}{lcc}
\hline & CALIZA ROJA & CALIZA GRIS \\
\hline Producto A & 10 YR 6/4 & 5 Y 6/2 \\
\hline Producto B & 10 YR 6/4 & 2,5 YR 7/0 \\
\hline Producto C & 10 YR 6/4 & 2,5 YR 6/2 \\
\hline Blanco & 10 YR 6/4 & 2,5 YR 6/2 \\
\hline
\end{tabular}

Gráfica 2. Caliza rojiza Alteración acelerada

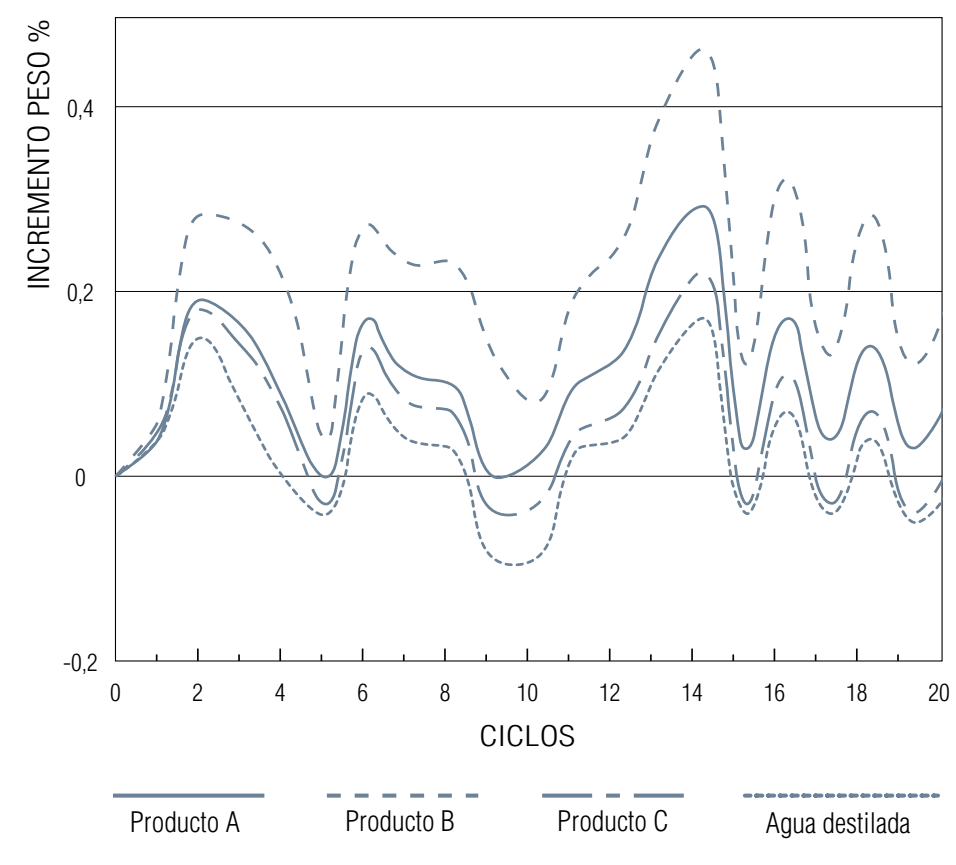


ㄴ
$\square$

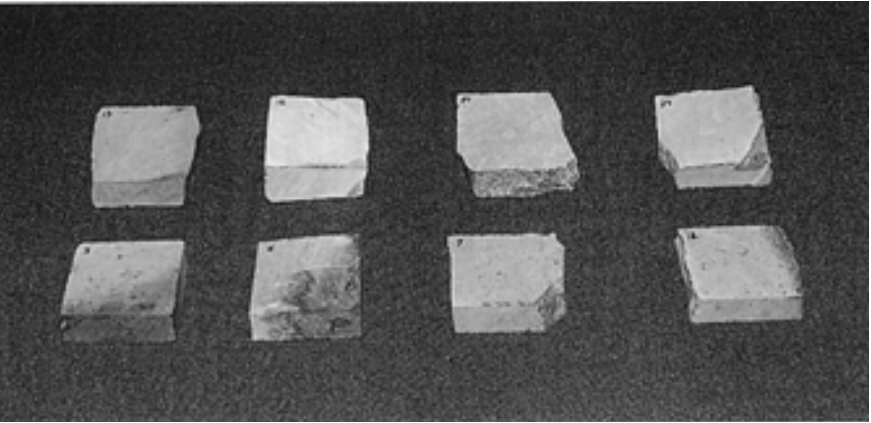

4.

6.

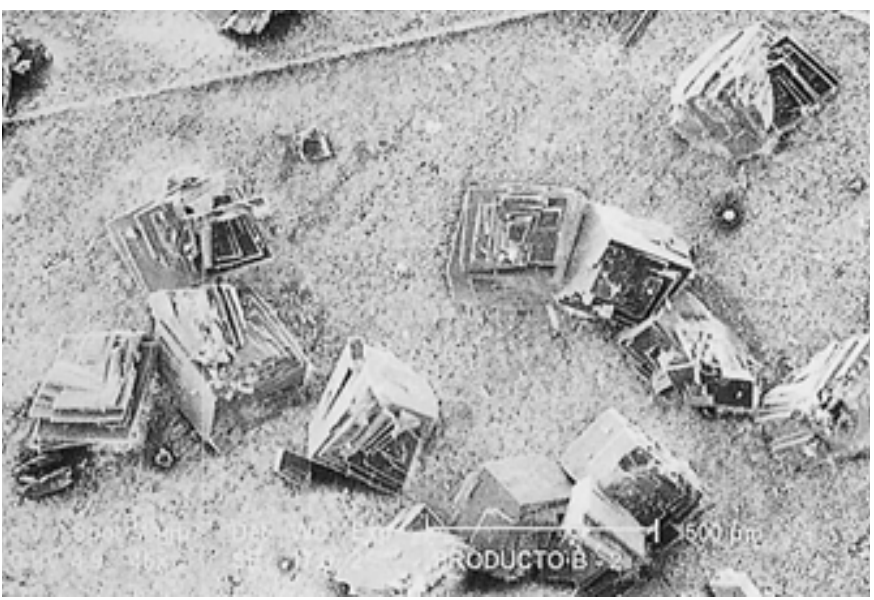
producto A. Para el agua destilada se mantiene el mismo peso (ganancia del 0,0।\%).

Nuevamente se ha observado al microscopio electrónico de barrido la caliza gris tratada con el producto $B$, detectándose la presencia de cristales semejantes a los que aparecen tras la impregnación por inmersión, aunque de menor tamaño. Esto puede explicarse por el hecho de que, en el segundo ensayo se ha provocado la cristalización y solubilización sucesivas repetidas veces, de forma que los cristales formados son más pequeños (fig. 4). Los resultados de un microanálisis de estos cristales coinciden con los anteriores.

En resúmen, la variación de peso de las probetas con cada uno de los tratamientos es muy baja, y la alteración microscópica también es poco significativa, por lo que puede considerarse que dichos tratamientos ejercen un efecto prácticamente inapreciable. do una ganancia de peso del $0,13 \%$ para el producto A, $0,26 \%$ para el producto $B$ y $0,04 \%$ para el produc-
to $C$. En el caso del agua destilada no se produce ga-

En la caliza gris se ha observado sin embargo una pérdida de peso del 0,07\% para el producto B, 0,03\% pa-

\section{Conclusiones}

No se observa ningún cambio significativo de color del material empleado con ninguno de los productos ensayados en el período de reacción estudiado, excepto en el caso del producto A, que causa una ligera coloración verdosa en la caliza gris por lo que no se aconseja su uso en zonas próximas a las estructuras emergentes.

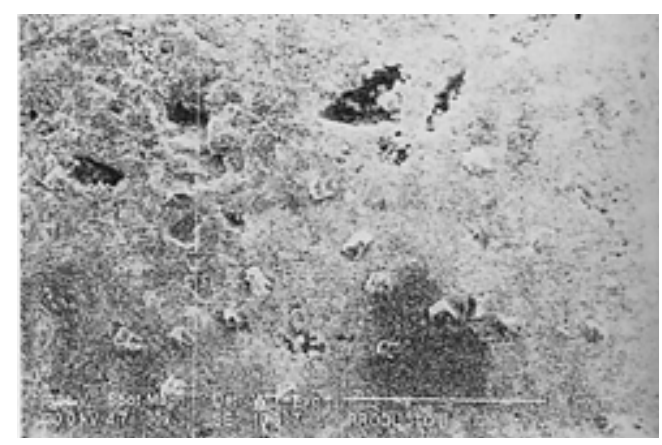

5.

Las propiedades físicas de las calizas no varían significativamente después del contacto con los herbicidas; por observación al SEM se aprecian en la superficie de la piedra, en el caso del producto B, cristales producidos posiblemente por reacción del mismo, aunque di-

cha reacción es muy superficial.

Los resultados se muestran en las gráficas 1 y 2 . Se
han observado resultados diferentes en los 2 tipos de

\section{Bibliografía}

- ASTM C-67, C-88, C-218, C-290, C-291.

- BONNIER, G. \& G. DE LAYENS (1988). Claves para la determinación de plantas vasculares. Ediciones Omega.

- DE LIÑÁN VICENTE, C. (1993). Vademecum de productos fitosanitarios y nutricionales. Ediciones agrotécnicas.

- DIN 52I04, 52।II, 52250.

- GARCÍA ROWE, J. \& C. SÁIZ JIMÉNEZ (|99|). Lichens and bryophites as agents of deterioration of building materials in Spanish Cathedrals. International Biodeterioration: Vol. 28, 15 |-163. Biodeterioration of Cultural Property (Ed. Robert J. Koestler). Elsevier, London and New York.

- ICR-CNR (1985). Assorbimento d'acqua per capillarità. Coefficiente di assorbimento capillare. Normal I I/85.

- ICR-CNR (198I). Esame delle caratteristiche morfologiche al microscopio elettronico a scansione (SEM). Normal 8/81.

- MUNSELL COLOR CO.INC. (1975). "Munsell soil color charts". Maryland, USA.

- NUGARI, M.P., P. PALLECHI \& D. PINNA (1993). Metodological evaluation of biocidal interference with stone materialsPreliminary laboratory tests. Conservation of stone and other materials: Vol. I, 205-2 I2. (M.J.Thiel). Rilem, London.

- OZENDA, P. \& G. CLAUZADE (1970). Les lichens. Étude biologique et flore illustrée.

- RILEM-VIa, VIb, V-2, V-3.

- SCHNABEL, L. (199I). The treatment of biological growths on stone: A conservator's viewpoint. International Biodeterioration: Vol. 28, 125-131. Biodeterioration of Cultural Property (Ed. Robert J. Koestler). Elsevier, London and New York.

- UNE 7-062, 7-136, 7-192, 22-174, 22-184, 22-193.

- VALDÉS, B., S. TALAVERA \& E. FERNANDEZ-GALIANO (eds.) (1987). Flora vascular de Andalucía occidental. Ketres. 